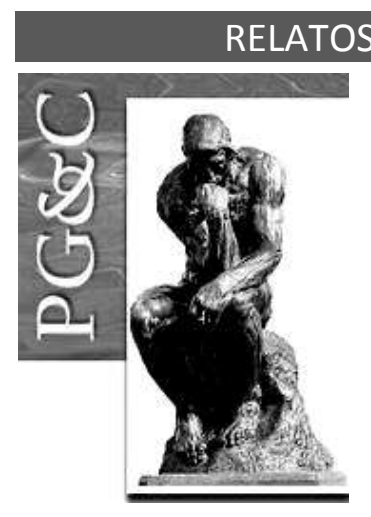

\title{
INOVAÇÃO E CULTURA ORGANIZACIONAL: CARACTERÍSTICAS PRESENTES EM CULTURAS DE INOVAÇÃO
}

\author{
Fernando Passeri Lavrado \\ Mestrando em Administração pelo Ibmec-RJ, Brasil. \\ E-mail: nando.lavrado@gmail.com \\ Nicole Bou Dib El-Khouri \\ Mestranda em Administração pelo Ibmec-RJ, Brasil. \\ E-mail: nicole.dib@hotmail.com \\ Cláudia Cristina Ramos Barbosa \\ Mestranda em Administração pelo Ibmec-RJ, Brasil. \\ E-mail: claudiacr.ramos@gmail.com \\ José Francisco de Carvalho Rezende \\ Doutor em Ciências da Administração pela Universidade Federal do Rio de \\ Janeiro, Brasil. Professor Colaborador Universidade Federal do Rio de \\ Janeiro, Brasil. \\ E-mail: rezende.jf@gmail.com
}

\begin{abstract}
Resumo
O estudo apresenta as definições de inovação e cultura organizacional e busca identificar, na literatura nacional e internacional, as principais características, os fatores e as dimensões de cultura organizacional que estão presentes em ambientes e organizações inovadoras no contexto da Quarta Revolução Industrial. Para alcançar tal objetivo, foi desenvolvida busca em bases de periódicos e artigos científicos, com a seleção adicional de textos a partir das referências dos artigos que foram encontrados naquelas bases. Foram selecionados 62 trabalhos identificados como mais aderentes ao propósito do estudo, dos quais 16 foram utilizados para buscar identificar as características habilitadoras e as barreiras de culturas de inovação. A partir da análise dos artigos, foi proposto um critério de categorização de fatores habilitadores e barreiras, descortinando-se a prevalência de soft skills. $\mathrm{O}$ fator da inovação tecnológica dentro da Quarta Revolução Industrial e como ele está afetando a esfera organizacional é de relevância acadêmica e prática nas empresas para auxiliar e orientar como o trabalho está sendo conduzido nesse novo contexto. Espera-se que o ensaio contribua para a compreensão da relação entre o ambiente propício à inovação e seus fatores que a impulsionam ou inibem, no ambiente empresarial.
\end{abstract}

Palavras-chave: Inovação. Cultura Organizacional. Organizações Inovadoras

\section{INNOVATION AND ORGANIZATIONAL CULTURE: CHARACTERISTICS PRESENT IN INNOVATION CULTURES}

\begin{abstract}
The study presents the definitions of innovation and organizational culture and seeks to identify, in national and international literature, the main characteristics, factors and dimensions of organizational culture that are present in innovative environments and organizations in the context of the Fourth Industrial Revolution. To achieve this, research was developed based on journals and scientific articles, with the additional selection of texts from the references of the articles that were found in scientific papers data bases. Sixty-two papers were selected, identified as most adherent to the research purpose,
\end{abstract}

Perspectivas em Gestão \& Conhecimento, João Pessoa, v. 10, n. 1, p. 88-106, jan./abr. 2020. DOI: http://dx.doi.org/10.21714/2236-417X2020v10n1p88

http://periodicos.ufpb.br/ojs2/index.php/pgc. ISSN: 2236-417X. Publicação sob Licença (cc) EY-NC-ND 
of which 16 were used to seek to identify the enabling characteristics and barriers of innovation cultures. Based on the analysis of the articles, a criterion for categorizing enabling factors and barriers was proposed, revealing the prevalence of soft skills. The factor of technological innovation within the Fourth Industrial Revolution and how it is affecting the organizational sphere is of academic and practical relevance in companies to assist and guide how work is being conducted in this new context. It is expected that this research contributes to the understanding of the relationship between the environment conducive to innovation and its factors that drive or inhibit it, in the business environment.

Keywords: Scientific Article. Methodology. Standards.

\section{INTRODUÇÃO}

A capacidade de adaptação de uma empresa frente às mudanças ambientais e às demandas do mercado influencia fortemente sua competividade. Nas últimas duas décadas e, mais recentemente, com o aumento da conectividade e da disponibilidade de tecnologias com potencial disruptivo, a capacidade de adaptação vem sendo abordada de maneira magnificada, inclusive em organizações operando mercados tradicionalmente estáveis.

As tecnologias da chamada Quarta Revolução Industrial (Indústria 4.0) tais como a manufatura aditiva (impressão 3D), a Internet das Coisas (IoT - Internet of Things), a Inteligência Artificial (IA), a Biologia Sintética, e os Sistemas Ciber Físicos (CPS - Cyber Physical Systems) permitem a fusão entre os mundos físico, biológico e digital e tem um impacto forte sobre a produtividade, a redução de custos, o controle sobre o processo produtivo e a própria natureza do trabalho humano. Segundo relatório do Fórum Econômico Mundial de 2018 (WEF - World Economic Forum), à proporção em que a Quarta Revolução Industrial ganha força, os gestores públicos e privados são confrontados com novo conjunto de incertezas em relação ao futuro das operações. A velocidade e o escopo das mudanças aumentam ainda mais a complexidade da "já desafiadora tarefa de desenvolver e implantar estratégias que promovam a produtividade e o crescimento inclusivo" (WEF, 2018).

Nesse contexto de transformação acelerada e incertezas, a capacidade de as empresas criarem e absorverem inovações que transformem o ambiente, constitui fator crítico e estratégico não somente para obtenção de vantagem competitiva como também para a própria sobrevivência das organizações. Drucker (1985), um dos principais consolidadores do pensamento gerencial contemporâneo, já considerava a inovação como um mecanismo para que os gestores possam aproveitar oportunidades advindas das mudanças, podendo ser aplicada de forma sistemática e disciplinada nas organizações.

Um número crescente de gestores busca transformar empresas em organizações inovadoras e criativas. Para Pisano (2019), embora culturas inovadoras sejam desejáveis, são difíceis de criar, implantar e manter. A despeito de a maioria dos líderes organizacionais afirmarem entender o que significa cultura inovadora, Pisano (2019) argui que, de fato, não há perfeita compreensão e que por isso a implementação nas organizações é difícil, exigindo disciplina - culturas inovadoras seriam paradoxais e exigiriam comportamentos aparentemente duais para serem realmente efetivas.

Para Pettigrew (1996), o conjunto complexo de valores, crenças e pressupostos, presente nas organizações, define a maneira que uma empresa conduz suas atividades, enquanto para Schein (1997) a cultura cria as condições de flexibilidade e adaptabilidade às mudanças ambientais.

Pesquisas acadêmicas sobre a relação entre cultura organizacional e inovação objeto do presente estudo - têm sido realizadas em busca da identificação dos fatores e das

Perspectivas em Gestão \& Conhecimento, João Pessoa, v. 10, n. 1, p. 88-106, jan./abr. 2020. 
dimensões culturais presentes e condicionantes da formação e manutenção de ambientes inovadores.

Fazendo frente à necessidade de descrever e tornar mais aplicáveis fatores que direcionam a inovação nas organizações, este trabalho apresenta revisão sobre definições e os usos dos construtos "inovação" e "cultura organizacional" identificados na literatura, tanto em autores seminais como em mais recentes, e busca verificar quais características e dimensões estão presentes em "culturas organizacionais voltadas para inovação" - innovation based corporate culture.

Assim, a questão direcionadora deste ensaio busca discutir, do ponto de vista do conhecimento pragmático (MENEGHETTI, 2007), a existência de um conjunto central de competências e capacidades organizacionais (WINTER, 2003; GREITEMANN et al.; LONGO et al., 2017), uma vez que imperativo da inovação como traço da cultura organizacional é um tópico de participação crescente na agenda de pesquisadores acadêmicos, tanto quanto na de gestores e praticantes em geral.

\section{INOVAÇÃO}

Para Schumpeter (1942), o impulso fundamental que mantém o motor capitalista em movimento advém de inovações, introduzidas por empresas capitalistas frente a bens de consumo, métodos de produção e de transporte, formas de organização industrial e de mercados. Tal "motor capitalista" seria como uma tempestade de destruição criativa, na qual o antigo mercado e incessantemente destruído enquanto o novo é criado.

Em relação aos conceitos de invenção e inovação, Garcia e Cantalone (2002) esclarecem que uma invenção não se torna uma inovação até que tenha sido processada por meio das funções de produção e marketing e estiver difundida no mercado. Por exemplo, conforme apontado por Drucker (1985), Leonardo da Vinci, um dos maiores gênios inventores da história, desenhou e projetou helicópteros e submarinos, porém nem essas nem outras de suas brilhantes ideias, presentes em suas anotações, foram convertidas em inovações com a tecnologia e os materiais dos séculos XIV e XV.

Inovação, "em seu sentido mais genérico, pode ser carcaterizada como algo novo para a organização. A palavra inovar, do latim, significa tornar novo, renovar, enquanto inovação traduz-se pelo ato de inovar" (MACHADO, 2004). Contudo, nem toda novidade necessariamente tem que possuir características de originalidade.

De forma análoga, é possível considerar que nem toda inovação é decorrente de uma nova invenção. A palavra "originalidade", oriunda da palavra original - do latim originalle - é relativa à origem, à qualidade de original, inicial, primordial, primitivo, originário. Novidade é originária do latim novitate - remete à qualidade ou caráter de novo, uma inovação, embora referente a algo já existente, um uso novo para algo já existente" (MACHADO, 2004).

A percepção de que alguma coisa é "nova" depende do contexto no qual é observada e utilizada. Neste diapasão, para Zaltman et al (1973) a definição de inovação pode ser entendida como uma ideia, uma prática ou um artefato material percebido como novo, relevante e único adotado em um determinado processo, área ou por toda a organização" (MACHADO, 2004).

A teoria de inovação, conforme Hogan e Coote (2014), tem suas origens nas indústrias de manufatura e de alta tecnologia. O construto "inovação" é comumente tratado na literatura como uma variável dicotômica ou um processo discreto.

Sobre os tipos de inovação, Damanpour (1991) aponta que ela pode ser do tipo técnica ou administrativa: a técnica relacionada aos produtos, serviços e processos de produção; as administrativas, relacionadas ao gerenciamento organizacional, que inclui tanto os processos de suporte administrativo da organização quanto a própria estrutura organizacional. Ainda

Perspectivas em Gestão \& Conhecimento, João Pessoa, v. 10, n. 1, p. 88-106, jan./abr. 2020. 
segundo Damanpour (1991), o grau e a extensão das mudanças, que inovações introduzem em práticas de uma organização, também são fatores que as classificam como inovações radicais (não rotineiras, de reorientação ou "ultimate innovations") ou incrementais (de rotina, de variação ou instrumentais). As inovações radicais são aquelas que produzem mudanças fundamentais nas práticas de uma organização e que apresentam claro afastamento das práticas existentes.

Damanpour (1991) também classifica a inovação como de produto ou de processo: de produto tem a ver com novos produtos ou serviços desenhados para atender às necessidades de determinados clientes ou de mercado; inovações de processos dizem respeito à introdução de novos elementos (tais como especificação de tarefas, novos materiais, mecanismos de fluxo de informações etc) nos processos de produção ou nas operações de serviços.

Christensen (2012), por sua vez, afirma que uma inovação pode ser de sustentação, utilizando tecnologias que possibilitam melhorar um produto ou serviço já estabelecidos, ou disruptiva que utiliza tecnologias de ruptura que trazem ao mercado uma proposição de valor diferente das disponíveis e que resultam em produtos ou serviços com desempenho normalmente inferior (no curto prazo), porém geralmente mais baratos e com algumas vantagens adicionais para os clientes.

De acordo com Christensen, Raynor e McDonald (2015), as trajetórias dos processos de inovações de sustentação normalmente são observadas em empresas já estabelecidas em um determinado mercado. Nesse processo de inovação, as empresas buscam melhorias de performance e qualidade de seus produtos/serviços para atender aos clientes que mais demandam (e normalmente os de maior margem de lucratividade) excedendo os requisitos de determinados segmentos e ignorando as necessidades de outros segmentos de clientes.

Por outro lado, tais autores entendem que as inovações disruptivas costumam iniciar com o ingresso de empresas menores focadas na camada dos clientes ignorados pelas empresas já estabelecidas, normalmente com produtos/serviços mais adequados - "bons o suficiente" - aos requisitos desta camada e com preços mais atraentes. Outro ponto de entrada de um processo de disrupção é verificado em novos mercados onde as empresas entrantes conseguem encontrar um caminho para transformar não-consumidores em consumidores.

Quando a trajetória do processo de evolução da inovação disruptiva atinge o mercado principal de empresas já estabelecidas, ocorre a disrupção, alterando o equilíbrio préexistente, erodindo primeiramente a participação de mercado das empresas já estabelecidas e depois a rentabilidade. Segundo Christensen, Raynor e McDonald (2015), normalmente a trajetória de disrupção passa despercebida pelas empresas estabelecidas, pois inicialmente estas consideram o produto das empresas entrantes inferiores ao seu (e assim interpretam como uma não-ameaça) ou então por se tratar de mercados novos onde não atuam e por conseguinte não monitoram.

Outra percepção corrente, indicada por Yoggi (2015), é de que inovação está associada a produtos ou serviços com elevada tecnologia embarcada, porém, nas organizações a inovação se apresenta de diversas maneiras com uma diversidade e complexidade bem maior do que a compreendida pelo público comum.

Hogan e Coote (2014) afirmam que nas indústrias manufatureiras, os resultados das inovações são tangíveis e novos produtos são gerados a partir de processo de inovação. Contudo, no contexto de serviços, por sua natureza intangível e perecível, pela proximidade do cliente e do prestador no processo de entrega do serviço, é difícil se diferenciar o que é inovação de produto e o que é inovação de processo. A entrega de uma solução de problema para um cliente, dentro do contexto de prestação de serviços profissionais, compreende tanto o serviço propriamente dito quanto o produto. 
A literatura recente, conforme citado em Hogan e Coote (2014), aponta para a perspectiva de que ao conceituar inovação seja necessária a inclusão de múltiplas dimensões. Alguns estudos, como Hogan et al. (2011), sugerem uma avaliação mais rica sobre inovação, indo além das classificações dicotômicas apresentadas, incluindo diversas dimensões como: inovação de produto, de processo, de mercado, de comportamento e de estratégia, oferecendo uma conceituação mais apropriada do construto para o contexto complexo de serviços profissionais.

A Organização para Cooperação e Desenvolvimento Econômico (OECD) define inovação como "a implementação de um produto (bem ou serviço) novo ou significativamente melhorado, ou um processo, ou um novo método de marketing, ou um novo método organizacional nas práticas de negócios, na organização do local de trabalho ou nas relações externas" (OECD, 2005).

As inovações também podem ser compreendidas pela perspectiva de processo com etapas que vão desde a percepção da ideia nova (não necessariamente original), passando pelo convencimento ou "venda" da novidade e alcançando a etapa da difusão da inovação, segundo Rogers e Shoemaker (1971). O processo de inovação, por meio de ações para implementação de novas ideias, busca resultar em melhorias e ganhos para a organização.

Em Machado (2007) é perceptível a noção de que a inovação é um processo, com ações deliberadas para gerar efetividade a partir de uma ideia que pode ser encontrada na equação utilizada pela $3 \mathrm{M}$, para representar este conceito, onde "Resultado = Ideia + Ação", conforme apontado por Gundling (1999).

Segundo Tidd e Bessant (2015), a habilidade de detectar oportunidades e tirar proveitos delas é um fator que move a inovação, "A Inovação é uma ferramenta específica dos empreendedores, pela qual exploram a mudança como uma oportunidade para um negócio ou serviço diferente. É possível de ser apresentada como uma disciplina, ensinada, aprendida e de ser praticada." (DRUCKER, 1985 p.19).

Algumas inovações não são desenvolvidas de maneira sistemática e organizada. Segundo Drucker (1985) existiriam inovadores "inspirados pelas musas" que geram inovações a partir do "flash de gênio", porém este tipo de inovação não pode ser replicado, ensinado ou aprendido. Drucker (1985) afirmava que a inovação intencional resultante de análise, sistematização e trabalho duro, que certamente cobre $90 \%$ de todas as inovações efetivas, é a que pode ser discutida como prática de inovação.

As organizações podem conduzir os processos de inovação de forma fechada exclusivamente com recursos próprios, normalmente através dos departamentos ou unidades internas de Pesquisa e Desenvolvimento, ou ainda de forma aberta utilizando modelos de negócios para ter acesso a ideias, tanto internas quanto externas à organização, em plataformas, arquiteturas e sistemas e criar valor ao mesmo tempo em que organiza mecanismos internos para poder usufruir parte deste valor como indicado por Bogers et al. (2018).

Chesbrough (2014) afirma que as inovações abertas são baseadas em fluxos de conhecimento gerenciados através das fronteiras organizacionais. Na inovação aberta a empresa deve abrir para agentes externos parte de sua estratégia, serviços e/ou estrutura para que estes possam interagir contribuindo com soluções e agregando valor ao seu próprio negócio e ao da organização. É uma mudança do paradigma de competição para o de colaboração parcial que traz para os gestores certa vulnerabilidade e desconforto (ARAÚJO, 2019).

O processo de inovação também poderia ser classificado, segundo Garcia e Cantalone (2002), como novidade real, descontínuo ou ainda como de inovação imitadora, arquitetural, modular, de aperfeiçoamento e evolucionário.

Perspectivas em Gestão \& Conhecimento, João Pessoa, v. 10, n. 1, p. 88-106, jan./abr. 2020. 
Para Yoggi (2015), essas e diversas tipologias do conceito de inovação podem ser encontradas na literatura e o conhecimento destas classificações pode ajudar aos gestores a identificar oportunidades de inovação na sua organização, considerando as variáveis de sua magnitude e formas de aplicação.

\section{CULTURA ORGANIZACIONAL}

A Teoria Comportamental da Administração, ou Teoria Behaviorista, iniciou a abordagem das ciências do comportamento com ênfase nas pessoas tendo por base o estudo da aprendizagem, estímulos e reações de respostas e hábitos dos indivíduos dentro das organizações, frente à comprovação experimental. De acordo com Balestrin (2002), o início dessa teoria foi marcado pelo livro "O comportamento Organizacional" de Hebert A. Simon no final da década de 1940 e seu conceito já foi definido por diversos autores desde então, conforme aponta Simonsen (1994).

Para Pettigrew (1996), a cultura organizacional seria um fenômeno que existe numa variedade de níveis diferentes, sendo que, no mais profundo, a cultura é pensada como um conjunto complexo de valores, crenças e pressupostos que definem os modos pelos quais uma empresa conduz seus negócios. Tal núcleo de crenças e pressupostos básicos é, naturalmente, manifesto nas estruturas, sistemas, símbolos, mitos e padrões de recompensas dentro da organização.

Schein (1997) define a cultura organizacional como responsável pela integração interna, relacionada aos funcionários da empresa, seu bem-estar e permanência dentro da organização e responsável pela adaptação externa: nessa relação com o ambiente externo, a cultura deverá prover condições de flexibilidade e adaptabilidade às mudanças ambientais e por consequência, administrar e integrar o ambiente interno para se ajustar ao ambiente externo e aos objetivos da organização, induzindo à busca por uma "cultura ideal".

Schein (1997) propõe que é possível determinar a cultura da empresa com base em níveis, que estão relacionadas ao grau de visibilidade de um fenômeno cultural dentro da organização aos olhos de um indivíduo, com destaque para:

- os artefatos visíveis, que são as vestimentas dos funcionários, a parte mobiliária, a arquitetura, ou seja, artefatos simples de serem reconhecidos na empresa.

- os valores, que marcam o comportamento dos funcionários, que são, pelo autor, considerados difíceis de serem detectados sem um processo de análise complexo e estruturado.

- os pressupostos inconscientes, que são os pressupostos básicos, porém por serem inconscientes são os mais difíceis de serem diagnosticados e por vezes, nem os indivíduos conseguem ter o conhecimento de seus próprios valores e crenças.

Os três níveis definidos por Schein (1997), são condizentes com os níveis externo, intermediário e centro anteriormente retratados por Tropennars (1994). O nível externo demonstra a parte "palpável", porém difícil de decifrar como língua, a comida, a arquitetura, os monumentos, a agricultura, os templos, os mercados, as vestimentas e a arte, assim como os artefatos visíveis de Schein. O nível intermediário é composto de normas e valores e o centro pelos princípios da existência.

Já Fleury \& Fleury (1996) alegam que os níveis externos da empresa são explícitos, formados por um conjunto de atividades que montam expressões culturais: ritos como de passagem, degradação, reforço, renovação, redução de conflito e integração.

Mintzberg (2000) alega que as interpretações do ambiente, das atividades e de artefatos é que irão compor a cultura. As interpretações são compartilhadas coletivamente em

Perspectivas em Gestão \& Conhecimento, João Pessoa, v. 10, n. 1, p. 88-106, jan./abr. 2020. 
um processo social, além de serem cognitivas, por essência e por isso não existe cultura individual.

Para Morgan (1996), a cultura é o processo de construção da realidade que faz com que as pessoas percebam eventos, ações, objetos, expressões e situações individuais de maneiras distintas e que vão construir as bases que tornam o comportamento de alguém compreensível - é a forma de representação da empresa no âmbito cultural, que irá variar de acordo com a sociedade e o contexto em que estiver inserida, o que explica como a mesma empresa situada em lugares diversos, pode constituir culturas organizacionais diferentes.

Segundo Schein (1997), a construção da identidade cultural da organização coincide com os pressupostos dos fundadores, líderes e primeiros funcionários da empresa, que, com o tempo, desenvolverão partindo da influência das experiências vivenciadas e também da cultura da região, do país e da profissão, uma cultura da própria organização, atribuindo caráter institucional.

Os autores até aqui revistados, aparentemente, convergem para uma proposição nuclear que encompassa a suma importância do fator humano dentro da organização, principalmente ao implementar mudança ou processo inovador. Observada a relevância da inovação e a busca por vantagens competitivas, seria necessário desenvolver cultura organizacional que facilite processos e que funcione como impulsionador estratégico para atingir a eficácia e eficiência - utilidade (MENEGHETTI, 2007).

Godóy e Peçanha (2009) e Jaskyte e Dressler (2005) consideram que a perspectiva cultural pode ampliar a compreensão do papel da cultura organizacional nos processos de inovação. Jamrog e Overholt (2004) utilizam a denominação "cultura da inovação" para destacar a cultura organizacional como facilitadora da implementação de tecnologia e inovação na atualidade. Estas autoras ainda descrevem que a partir da construção de estudos empíricos, os autores Mavondo e Farrel (2003), Martins e Terblanche (2003), Solomon, Winslow e Tarabishy (2002), Stringer (2000) e Ahmed (1998) mostraram que organizações inovadoras possuem certas características culturais distintas das demais.

Mais recentemente, a importância do Capital Humano como elemento central à existência de uma cultura organizacional pujante e capaz de originar vantagens competitivas sustentáveis (LACERDA, 2011) vem recebendo atenção adicional em vista do eventual enfrentamento de questões locais em contraste às globais. Nesse sentido, Khan e Cox (2017) identificaram, ao testar as dimensões propostas por Hofested em relação à variáveis capazes de identificar sociedades inovativas que são predominantes os valores culturais: individualismo, harmonia, pragmatismo e indulgência.

\section{PROCEDIMENTOS}

De maneira a identificar, descrever e discutir a existência de um conjunto central de competências e capacidades organizacionais habilitadoras de uma cultura corporativa baseada na inovação, foi realizada revisão bibliográfica, explorando conceitos e formulações úteis, passíveis de serem acessados e aplicados tanto por acadêmicos quanto praticantes.

Para desenvolvimento deste estudo foi realizada busca em bases de periódicos e artigos científicos (Google Schoolar, Science Direct e Ebscohost) - disponíveis e gratuitas no contexto da instituição de ensino sede da pesquisa - e artigos sugeridos por e-mail pelo sistema de sugestões automáticas da base Science Direct. Além disso foram selecionados textos adicionais a partir das referências dos artigos que foram encontrados nessas bases.

A partir dos campos de título e de resumos, a busca utilizou, as seguintes palavraschave: Inovação; Cultura Organizacional; Organizações Inovadoras; Cultura de Inovação incluindo as mesmas palavras traduzidas para o inglês. Além disso, foi realizada triagem dos

Perspectivas em Gestão \& Conhecimento, João Pessoa, v. 10, n. 1, p. 88-106, jan./abr. 2020. 
resultados das buscas a partir da leitura do resumo e considerações finais dos textos, selecionado os considerados como mais aderentes ao propósito deste trabalho.

Foram encontrados 62 estudos, dos quais 16 foram utilizados para buscar identificar características habilitadoras e barreiras de culturas de inovação e os demais para as definições dos construtos inovação e cultura organizacional, apresentados nos tópicos anteriores.

A partir das características, encontradas na literatura - que habilitam ou restringem o desenvolvimento de uma cultura corporativa baseada na inovação - innovation based corporate culture - foram identificadas, a posteriori, categorias e enquadradas as contribuições consideradas mais significativas para atendimento à discussão da questão de fundo aqui estudada.

O desenvolvimento do estudo seguiu a forma de ensaio-teórico, de modo a que o leitor concorde ou discorde reflexivamente, permitindo o movimento de criar a sensação de desconforto e insatisfação, eventualmente, ao longo da leitura (MENEGHETTI, 2011).

O recorte bibliográfico permitiu discutir pragmaticamente, sob os pontos de vista das características habilitadoras e das barreiras, aspectos das culturas corporativas baseadas na inovação.

\section{CARACTERÍSTICAS DE CULTURAS CORPORATIVAS BASEADAS NA INOVAÇÃO}

A cultura de uma determinada organização pode conter fatores que tanto incentivam quanto também levantam barreiras à inovação. Da cultura são derivados parâmetros para estabelecer que comportamentos são considerados desejáveis e incentivados e quais são considerados inaceitáveis. Fatores como "encorajamento das lideranças" e do "grupo de trabalho", "grau de liberdade" e "autonomia" e "provimento de recursos" são aspectos que favorecem o ambiente inovador enquanto o fator de "controle" seria um aspecto que inibiria a criatividade e inovação. (Mc LEAN, 2005; BRUNO-FARIA; FONSECA, 2014). Outros fatores tais como "distância do poder" e "evitação das incertezas" seriam aspectos inibidores e devem ser objeto de atenção dos gestores (ÇAKAR; ERTÜK, 2010; KAASA; VADI, 2010; BRUNO-FARIA; FONSECA, 2014).

Pisano (2019) entende que para uma cultura de inovação ter efetividade é necessário equilíbrio entre comportamentos tidos como agradáveis e favoráveis com comportamentos que por vezes podem ser percebidos como comportamentos mais rigorosos e inibidores. Uma cultura inovadora pode apresentar "tolerância ao fracasso", mas essa característica deve ser limitada por uma "intolerância à incompetência". Culturas de inovação devem incentivar a "disposição para experimentação", porém ao mesmo tempo devem cobrar "forte disciplina" para que os experimentos tenham valor potencial de "aprendizado". Um ambiente que forneça "segurança psicológica" onde as pessoas podem se expressar de forma aberta e sem medo de represálias exige que a "franqueza", que não é necessariamente algo agradável, possa ser exercida de forma plena. É necessário que a abertura de opinião seja uma mãodupla. Assim como as pessoas querem ser ouvidas tem que haver tolerância para receber críticas. Os ambientes inovadores também possuem características de "culturas colaborativas", porém é necessário que sejam também focados na "responsabilidade individual". Pisano (2019) afirma que organizações "culturamente niveladas" normalmente geram maior diversidade de ideias do que organizações "culturamente hierarquizadas", porém exigem "forte liderança" para o estabelecimento de prioridades estratégicas.

A literatura aponta "uma ligação muito forte entre inovatividade e cultura" (DOBNI, 2008), contudo ainda há espaço para que seja explorada a forma como ocorrem essas relações (BRUNO-FARIA; FONSECA, 2014).

Dentre os artigos nacionais aqui analisados, os de Machado (2007), e de Machado et al. (2013), ambos quantitativos, apresentam a análise da cultura de inovação sob a ótica de

Perspectivas em Gestão \& Conhecimento, João Pessoa, v. 10, n. 1, p. 88-106, jan./abr. 2020. 
elementos da cultura organizacional e sob a perspectiva de fatores que influenciam em favor da inovação. Em tais trabalhos foram observados, de forma integral ou parcial, os seguintes elementos da cultura organizacional: "valores"; "crenças e pressupostos"; "ritos, rituais e cerimônias"; "histórias e mitos"; "normas"; "comunicação"; "heróis"; "tabus"; e "artefatos e símbolos".

Segundo Machado et al. (2013), os nove elementos da cultura observados são uma combinação dos indicados nos trabalhos de Schein (1984) e Trompenaars (1994) que indicam como centrais valores e, crenças e pressupostos com os elementos perceptíveis fomentados pelos elementos centrais, conforme argumentação de O'Reilly, Chatman e Caldwell (1991) que são: os ritos, rituais e cerimônias, normas, artefatos entre outros.

Além dos elementos da cultura acima Machado (2007) lista os fatores que também influenciam um ambiente inovador: "eficiência percebida com a inovação"; "incerteza sobre a inovação"; "escassez de recursos"; "padronização de procedimentos"; "grau de influência nas decisões";" expectativas de prêmios e sanções"; "liderança do time de inovação"; "liberdade para expressar dúvidas"; "aprendizagem encorajada"; "dependência de recursos"; "formalização"; "eficiência percebida"; "influência"; "ambiente econômico"; "estrutura de mercado e concorrência"; "ambiente tecnológico"; "ambiente demográfico"; "ambiente legal/regulador"; "grau de novidade"; "dimensão da inovação"; "estágio da inovação"; "tempo dedicado à inovação"; "frequência de comunicação"; "problemas identificados"; "conflitos"; "processo de resolução de conflitos"; "complementaridade"; "consenso/ conflito"; "frequência de comunicação"; e "duração do relacionamento".

Esses vinte e nove fatores derivam da metodologia Minnesota Innovation Survey (MIS) do Minnesota Innovation Research Program (MIRP) "desenvolvida para investigar categorias ou variáveis que descrevem as inovações, como são incentivadas e que forças as influenciam" (MACHADO, 2007). A metodologia considera que o processo de inovação é decorrente de uma séríe de eventos temporais ligados aos seguintes componentes-chave: "ideias", "pessoas", "transações", "contexto" e "resultados", segundo Van de Ven, Angle e Poole (2000). Os diagnósticos de Machado (2007) e Machado e Vasconcelos (2007), encontraram os 9 primeiros fatores da lista acima nas organizações pesquisadas.

O estudo de Machado, Carvalho e Heinzmann (2012) destaca a "baixa distância do poder" e o "alto ambiente coletivista" como características percebidas no ambiente de inovação.

No trabalho, também de abordagem quantitativa, de Scarpin e Machado (2015) destacam-se as seguintes dimensões: "Resultados", "Processos", "Recursos", "Liderança", "Relacionamento Interno ao Grupo de Inovação" e "Efetividade de Relacionamentos" como presentes no ambiente propício ao desenvolvimento de inovações. Uma cultura organizacional congruente com "pequena distância do poder" e "alto coletivismo".

Já Bruno-Faria e Fonseca (2014) apresentam uma ampla revisão de literatura, analisando quarenta artigos sobre o tema cultura de inovação buscando caracterizar o seu significado e apresentar diversos modelos teóricos que procuram compreender como ocorre a relação entre cultura e inovação no contexto organizacional. Bruno-Faria e Fonseca (2014) identificaram um conjunto de fatores que afetam a cultura de inovação e destacando os de: "atuação da liderança"; "comunicação e compartilhamento de informações"; "correr riscos"; "intenção de inovar e ser bem-sucedido" ou "estratégia de inovação".

Em outro estudo sobre medida de cultura de inovação, Bruno-Faria e Fonseca (2015) identificam, partindo de quatro abordagens teóricas sobre culturas de inovação, algumas dimensões e fatores As dimensões e fatores relacionados ao contexto interno de suporte da organização são: "suporte"; "suporte da gerência"; "contexto de implementação" e "eleitorado organizacional (constituency)". Na estratégia da organização: "estratégia"; "intencionalidade"; "propensão para inovação"; "orientação para inovação estratégica",

Perspectivas em Gestão \& Conhecimento, João Pessoa, v. 10, n. 1, p. 88-106, jan./abr. 2020. 
"objetivos e inovação". No relacionamento com o contexto externo: "orientação para o cliente"; "orientação para o mercado" e "orientação para mercados futuros". No contexto interno da organização e conteúdo da cultura: "relação de confiança"; "comportamento que encoraja a inovação"; "orientação para a aprendizagem"; "disposição para correr riscos", "aprendizagem organizacional"; "criatividade" e "empoderamento"; e "orientação para valor". Nesse estudo os autores destacam que uma organização é considerada inovadora na presença dos seguintes aspectos: "percepção dos resultados da inovação pela organização"; "relacionamento com clientes;" "conteúdo da cultura"; "envolvimento dos indivíduos com atividades de inovação"; "percepção de resultados pela sociedade" e "características e ações da liderança".

No framework de inovação proposto por Yoggi (2017) é possível perceber características relacionadas ao "alinhamento com objetivos estratégicos", à "otimização de recursos da área de inovação" e também a importância do "feedback" e o "reconhecimento" dos colaboradores.

Hogan e Coote (2014) analisam quantitativamente os seguintes elementos da cultura organizacional: "valores"; "normas"; e "artefatos" que a revisão da literatura, segundo os autores, sugere motivar comportamentos voltados à inovação. Foram analisadas as seguintes oito dimensões de valores que incentivariam comportamentos inovativos: "sucesso"; "abertura e flexibilidade"; "comunicação interna"; "competência e profissionalismo"; "cooperação interfuncional"; "responsabilidade"; "valorização"; e "tomada de riscos" (HOGAN E COOTE, 2014). Esses autores também destacam que a cultura organizacional moldada pelos gestores por meio de valores, normas e artefatos encoraja e suporta comportamentos inovativos, particularmente os "comportamentos das lideranças" tais como mostrar "respeito pelos empregados" e valorizá-los por meio de "reconhecimentos das contribuições" na direção dos objetivos organizacionais. Hogan e Coote (2014) concluem que a gestão, ao instilar valores e normas nos artefatos organizacionais, pode conduzir a empresa a níveis mais altos de inovação; sugerem que os artefatos também podem ser um poderoso mecanismo de "comunicação e endosso dos valores" que suportam a criatividade e inovação.

Naqshbandi et al. (2014) realizaram estudo sobre os tipos de cultura que habilitam ou retardam a inovação aberta concluindo que "culturas hierárquicas" se apresentam como barreiras e fatores que retardam ambos tipos de inovação aberta (inbound e outbound) enquanto que as "culturas altamente integradoras" impactam de forma habilitadora somente e um tipo de inovação aberta (outbound).

Para Rocha e Souza (2019), as principais capacidades que as empresas precisam desenvolver e gerenciar em negócios digitais disruptivos, destacando e detalhando as "capacidades de inovação", "capacidades de liderança" e "capacidades de gestão".

Brettel, Chomik e Flatten (2014) indicam que "cultura hierárquica" tem impacto negativo e que "cultura de grupo", "cultura de desenvolvimento" e "culturas racionais" geram impacto positivo em ambientes de inovação e empreendedorismo.

O estudo de Hock, Clauss e Schulz (2016) aponta que culturas orientadas à inovação adotam as seguintes capacidades: "sensibilidade estratégica", "compromisso coletivo" e "fluidez de recursos".

O Quadro 1 apresenta as principais características habilitadoras para culturas de inovação enquanto o Quadro 2 apresenta as principais barreiras que foram encontradas na literatura pesquisada. As características e barreiras foram categorizadas agrupando as palavras e expressões citadas, nos artigos revisitados e em outros textos constantes das referências, em palavras-chave que buscam sintetizar um significado comum. 
Quadro 1 - Características Habilitadoras de Culturas Corporativas Baseadas na Inovação

\begin{tabular}{|c|c|c|}
\hline Skill & Dimensão & Estudos \\
\hline Hard & $\begin{array}{l}\text { Processos: processos; padronização de } \\
\text { procedimentos }\end{array}$ & $\begin{array}{l}\text { Scarpin e Machado (2015); Machado (2007 } \\
\text { p.22); Machado e Vasconcelos (2007). }\end{array}$ \\
\hline Hard & $\begin{array}{l}\text { Recursos: provimento de recursos; } \\
\text { recursos; capacidade de organizar os } \\
\text { recursos necessários para responder as } \\
\text { oportunidades (capacidade de inovação); } \\
\text { escassez de recursos em níveis moderados; } \\
\text { otimizar os recursos da área de inovação; } \\
\text { fluidez de recursos }\end{array}$ & $\begin{array}{l}\text { Scarpin e Machado (2015), Mc Lean (2005); } \\
\text { Bruno-Faria e Fonseca (2014); Rocha e Souza } \\
\text { (2019 p.260); Machado (2007 p.22); Machado e } \\
\text { Vasconcelos (2007); Yoggi (2017); Hock, Clauss e } \\
\text { Schulz (2016). }\end{array}$ \\
\hline Hard & $\begin{array}{l}\text { Resultados: resultados; percepção dos } \\
\text { resultados da inovação pela organização; } \\
\text { percepção de resultados pela sociedade; } \\
\text { orientação para valor; sucesso; forte } \\
\text { disciplina; Eficiência Percebida; cultura } \\
\text { racional }\end{array}$ & $\begin{array}{l}\text { Bruno-Faria e Fonseca (2014); Bruno-Faria e } \\
\text { Fonseca (2015 p.58) citam mais } 3 \text { artigos; } \\
\text { Scarpin e Machado (2015); Hogan e Coote (2014 } \\
\text { p. 1612) citam mais } 7 \text { artigos; Pisano (2019); } \\
\text { Machado (2007 p.21); Machado e Vasconcelos } \\
\text { (2007); Brettel, Chomik e Flatten (2014). }\end{array}$ \\
\hline Soft & $\begin{array}{l}\text { Aceitação de Riscos: tomada de riscos; } \\
\text { disposição para correr riscos; tolerância ao } \\
\text { fracasso; correr riscos; capacidade de } \\
\text { tomar riscos (capacidade de inovação); } \\
\text { aprendizagem encorajada. }\end{array}$ & $\begin{array}{l}\text { Hogan e Coote (2014 p.1612) citam mais } 4 \\
\text { artigos; Bruno-Faria e Fonseca (2014 p.391) } \\
\text { citam mais } 6 \text { artigos Bruno-Faria e Fonseca ( } 2015 \\
\text { p.58) citam mais } 3 \text { artigos; Pisano (2019); Rocha } \\
\text { e Souza (2019 p.260); Machado (2007); Machado } \\
\text { e Vasconcelos (2007); Brettel, Chomik e Flatten } \\
\text { (2014). }\end{array}$ \\
\hline Soft & $\begin{array}{l}\text { Aprendizagem: aprendizagem } \\
\text { organizacional; orientação para } \\
\text { aprendizagem; aprendizado; aprendizagem } \\
\text { encorajada; lições aprendidas. }\end{array}$ & $\begin{array}{l}\text { Bruno-Faria e Fonseca (2015 p.58) citam mais } 3 \\
\text { artigos; Pisano (2019); Machado (2007 p.22); } \\
\text { Machado e Vasconcelos (2007). }\end{array}$ \\
\hline Soft & $\begin{array}{l}\text { Autonomia e Abertura: grau de liberdade; } \\
\text { autonomia; abertura e flexibilidade; } \\
\text { empoderamento; segurança psicológica; } \\
\text { franqueza; grau de influência nas decisões; } \\
\text { Liberdade para expressar dúvida. }\end{array}$ & $\begin{array}{l}\text { Mc Lean (2005); Bruno-Faria e Fonseca (2014); } \\
\text { Bruno-Faria e Fonseca (2015 p.58) citam mais } 3 \\
\text { artigos; Hogan e Coote (2014, p.1612) citam } \\
\text { mais } 4 \text { artigos; Pisano (2019); Machado (2007 } \\
\text { p.22); Machado e Vasconcelos (2007). }\end{array}$ \\
\hline Soft & $\begin{array}{l}\text { Colaboração e Cooperação: grupo de } \\
\text { trabalho; culturas colaborativas; alto } \\
\text { coletivismo; cooperação interfuncional; } \\
\text { alto ambiente coletivista; cultura de grupo, } \\
\text { compromisso coletivo. }\end{array}$ & $\begin{array}{l}\text { Pisano (2019), Mc Lean (2005); Bruno-Faria e } \\
\text { Fonseca (2014); Scarpin e Machado (2015); } \\
\text { Hogan e Coote (2014 p.1612) citam mais } 5 \\
\text { artigos; Machado, Carvalho e Heinzmann (2012); } \\
\text { Brettel, Chomik e Flatten (2014); Hock, Clauss e } \\
\text { Schulz (2016). }\end{array}$ \\
\hline Soft & $\begin{array}{l}\text { Competência: competência e } \\
\text { profissionalismo, intolerância à } \\
\text { incompetência; capacidades de inovação. }\end{array}$ & $\begin{array}{l}\text { Pisano (2019); Hogan e Coote (2014 p. 1612) } \\
\text { citam mais } 3 \text { artigos; Rocha e Souza (2019). }\end{array}$ \\
\hline Soft & $\begin{array}{l}\text { Comunicação: comunicação; comunicação } \\
\text { interna; comunicação e compartilhamento } \\
\text { de informações; comunicação e endosso } \\
\text { dos valores; capacidades de comunicação } \\
\text { para desenvolver o comprometimento dos } \\
\text { empregados (capacidade de liderança). }\end{array}$ & $\begin{array}{l}\text { Bruno-Faria e Fonseca (2014 p. 391) citam mais } 7 \\
\text { artigos, Hogan e Coote (2014 p. 1612) citam mais } \\
7 \text { artigos; Rocha e Souza (2019 p.260). }\end{array}$ \\
\hline Soft & $\begin{array}{l}\text { Cultura Não Hierarquizada: culturalmente } \\
\text { niveladas; culturas altamente } \\
\text { integradoras; }\end{array}$ & Pisano (2019), Naqshbandi et al. (2014). \\
\hline
\end{tabular}

Perspectivas em Gestão \& Conhecimento, João Pessoa, v. 10, n. 1, p. 88-106, jan./abr. 2020. 


\begin{tabular}{|c|c|c|}
\hline Skill & Dimensão & Estudos \\
\hline Soft & $\begin{array}{l}\text { Estratégia: estratégia; estratégia de } \\
\text { inovação; intenção de inovar e ser bem } \\
\text { sucedido; intencionalidade, propensão } \\
\text { para inovação; orientação para inovação } \\
\text { estratégica; objetivos e inovação; } \\
\text { alinhamento com objetivos estratégicos; } \\
\text { Categorização dos macrotemas; } \\
\text { sensibilidade estratégica }\end{array}$ & $\begin{array}{l}\text { Bruno-Faria e Fonseca (2014 p. 391) citam mais } 5 \\
\text { artigos; Bruno-Faria e Fonseca (2015 p.58) citam } \\
\text { mais } 4 \text { artigos; Yoggi (2017); Hock, Clauss e } \\
\text { Schulz (2016). }\end{array}$ \\
\hline Soft & $\begin{array}{l}\text { Liderança: forte liderança; encorajamento } \\
\text { das lideranças; comportamentos que } \\
\text { encoraja a inovação; liderança; atuação } \\
\text { das lideranças; suporte da gerência; } \\
\text { características e ações da liderança; } \\
\text { capacidades das lideranças; capacidades } \\
\text { de gestão; grau de liderança dos times de } \\
\text { inovação }\end{array}$ & $\begin{array}{l}\text { Pisano (2019); Scarpin e Machado (2015); Bruno- } \\
\text { Faria e Fonseca (2014 p.390) citam mais } 12 \\
\text { artigos; Bruno-Faria e Fonseca (2015 p.58) citam } \\
\text { mais } 3 \text { artigos; Hogan e Coote (2014); Rocha e } \\
\text { Souza (2019 p .260); Machado (2007); Machado } \\
\text { e Vasconcelos (2007). }\end{array}$ \\
\hline Soft & $\begin{array}{l}\text { Proximidade do Poder: pequena distância } \\
\text { do poder; baixa distância do poder }\end{array}$ & $\begin{array}{l}\text { Scarpin e Machado (2015); Machado, Carvalho e } \\
\text { Heinzmann (2012). }\end{array}$ \\
\hline Soft & $\begin{array}{l}\text { Reconhecimento: respeito pelos } \\
\text { empregados; valorização; } \\
\text { reconhecimentos das contribuições; } \\
\text { capacidade de melhorar a satisfação dos } \\
\text { empregados através de reconhecimento; } \\
\text { expectativa de prêmios e sanções; } \\
\text { feedback; reconhecimento }\end{array}$ & $\begin{array}{l}\text { Hogan e Coote (2014 p. 1612) citam mais } 6 \\
\text { artigos; Rocha e Souza (2019 p. 260); Machado } \\
\text { (2007 p.22); Machado e Vasconcelos (2007); } \\
\text { Yoggi (2017). }\end{array}$ \\
\hline Soft & $\begin{array}{l}\text { Relacionamentos: relacionamento interno } \\
\text { ao grupo de inovação; efetividade de } \\
\text { relacionamentos; relacionamento com } \\
\text { clientes; orientação para o cliente; } \\
\text { orientação para o mercado; orientação } \\
\text { para mercados futuros; capacidade de } \\
\text { criar e desenvolver rede de } \\
\text { relacionamentos nacionais e internacionais } \\
\text { (capacidade de inovação); cultura de } \\
\text { desenvolvimento }\end{array}$ & $\begin{array}{l}\text { Scarpin e Machado (2015); Bruno-Faria e } \\
\text { Fonseca (2015 p.58) citam mais } 3 \text { artigos; Rocha } \\
\text { e Souza (2019 p.260); Brettel, Chomik e Flatten } \\
\text { (2014). }\end{array}$ \\
\hline Soft & $\begin{array}{l}\text { Responsabilidade: responsabilidade } \\
\text { individual; responsabilidade }\end{array}$ & $\begin{array}{l}\text { Pisano (2019), Hogan e Coote (2014 p. 1612) } \\
\text { citam mais } 4 \text { artigos. }\end{array}$ \\
\hline
\end{tabular}

Fonte: Os autores

Quadro 2 - Barreiras para Culturas Corporativas Baseadas na Inovação

\begin{tabular}{|c|l|l|}
\hline Skill & \multicolumn{1}{|c|}{ Dimensão } & \multicolumn{1}{c|}{ Estudos } \\
\hline Hard & Controles: Controle & Mc Lean (2005); Bruno-Faria e Fonseca (2014). \\
\hline Soft & $\begin{array}{l}\text { Aversão ao Risco: evitar incerteza; } \\
\text { incerteza sobre a inovação }\end{array}$ & $\begin{array}{l}\text { Çakar e Ertük (2010), Kaasa e Vadi (2010), Bruno- } \\
\text { Faria e Fonseca (2014); Machado (2007 p. 21); } \\
\text { Machado e Vasconcelos (2007). }\end{array}$ \\
\hline Soft & $\begin{array}{l}\text { Cultura Hierarquizada: culturalmente } \\
\text { hierarquizadas; cultura hierárquica; cultura } \\
\text { hierárquica }\end{array}$ & $\begin{array}{l}\text { Pisano (2019), Naqshbandi } \text { et al. (2014); Brettel, } \\
\text { Chomik e Flatten (2014). }\end{array}$ \\
\hline Soft & Distância do Poder: distância do poder & $\begin{array}{l}\text { Çakar e Ertük (2010); Kaasa e Vadi (2010); Bruno- } \\
\text { Faria e Fonseca (2014). }\end{array}$ \\
\hline
\end{tabular}

Fonte: Os autores

Perspectivas em Gestão \& Conhecimento, João Pessoa, v. 10, n. 1, p. 88-106, jan./abr. 2020. 


\section{CONSIDERAÇÕES FINAIS}

O fator da inovação tecnológica dentro da Quarta Revolução Industrial (Indústria 4.0), e como ele está afetando a esfera organizacional, apresenta relevância acadêmica e prática nas empresas para auxiliar e orientar como as estratégias e as operações de uma organização estão sendo conduzida nesse novo contexto.

Os achados do estudo proporcionaram diálogo da cultura e do comportamento organizacional, com a inovação corporativa, fundamentando bases para um modelo aderente à atual configuração da economia.

O reconhecimento e o contraste de proposições dos autores compulsados no tocante às interações entre Cultura Organizacional e Inovação destacou e oportunizou a formulação de uma proposição central: a gestão da inovação é um processo eminentemente multidimensional, baseado na aplicação balanceada da diversidade de capabilities organizacionais (Rezende, 2006), que podem ser do tipo hard skill ou soft skill, com prevalência daquelas de cunho relacional e comportamental (soft) sobre as procedimentais (hard).

Enquanto há uma certa equivalência entre fatores hard e soft na condição de habilitadores da inovação, nas barreiras prevalecem fatores soft: é essencial manter o foco quanto à difusão da inovação baseada na cultura organizacional para que (i) líderes e indivíduos de referência interna fortaleçam valores e processos com impacto positivo no desenvolvimento de projetos de inovação; e (ii) investiguem quais as práticas organizacionais em cada ponto de alavancagem da cultura de inovação, relacionando os elementos da cultura organizacional com propostas para gestão da inovação - trabalhando em linha com sensibilização, educação e participação de grande parte da empresa (MORSCHE et al., 2013).

Em linha, foi possível identificar que os impactos da inovação afetam diretamente a empresa como um todo e influenciam a cultura organizacional, ao mesmo tempo, dependendo dessa cultura para difundir o processo da inovação (Alvim, 2012; OCDE, 2005). Os fatores achados e citados por McLEAN (2005), Bruno-Faria e Fonseca (2014), são considerados aspectos que podem favorecer ou não o ambiente inovador, como por exemplo, encorajamento das lideranças e do grupo de trabalho, grau de liberdade e autonomia e provimento de recursos que são todos positivos e impulsionadores.

De acordo com Schoeninger, Pacini e Casagranda (2015), O ambiente organizacional não seria constituído unicamente de produtos e processos, mas também pela autonomia promovida que estimula a criatividade e a inovação dos funcionários, para que apresentem novas soluções, projetos, processos, diferenciação de qualidade no produto, alinhado com o trabalho de equipe - sintonizado com comportamento e cultura inovadores e em sintonia com as Mc Lean (2005), Bruno-Faria e Fonseca (2014, 2015), Hogan e Coote (2014).

O ambiente e a dinâmica organizacional como um todo são fatores decisivos para as empresas se adaptarem a novos contextos tendo como norte a criação e absorção da cultura organizacional baseada na inovação.

Dessa forma, "os colaboradores criativos, ou aqueles que têm liberdade para a criatividade dentro da organização, têm potencial para resolver problemas mais complexos, quando trabalhado em grupo, dentro da própria organização, as chances de bons resultados são ainda maiores, isso é possível de ser visto em organizações que possuem uma cultura inovadora, possibilitando que os colaboradores auxiliem em todo o processo." (TIDD; BESSANT; PAVITT, 2003 apud SCHOENINGER; PACINI; CASAGRANDA, 2015).

Para futuras pesquisas a partir dos conceitos e conhecimentos recuperados e listados foram identificadas oportunidade de contrastar casos em que haja traços culturais distintos para buscar implicações no estilo e no resultado da inovação; além da sempre presente oportunidade de aprofundar quantitativamente as relações entre as diversas variáveis, fatores

Perspectivas em Gestão \& Conhecimento, João Pessoa, v. 10, n. 1, p. 88-106, jan./abr. 2020. 
e construtos apresentados nos Quadros 1 e 2 - sob a óptica de dirigentes, gestores, funcionários e stakeholders em geral.

Em vista da existência de vínculos e interações entre cultura organizacional e performance da inovação, é razoável questionar se o perfil organizacional de cada empresa (cultura da organização) vai influenciar no fato de a empresa ser mais adepta à implementação de artefatos e produtos inovadores.

Ao presente estudo podem ser atribuídas as seguintes limitações: (i) quantidade de literatura disponível vinculando teoria comportamental e cultural da organização ao processo de inovação; e (ii) não foi realizado nenhum contato ou estudo e pesquisa sobre a repercussão da cultura organizacional como direcionadora da inovação perante a óptica dos funcionários da empresa.

Por fim, é esperado que o presente ensaio contribua para a compreensão da relação entre o ambiente propício à inovação e fatores que a impulsionam ou inibem.

\section{REFERÊNCIAS}

AHMED, P. K. Culture and climate for innovation. European journal of innovation management, v. 1, n. 1, p. 30-43, 1988.

ALVIM, J. Avaliação dos impactos da inovação no desempenho das empresas. Belo Horizonte: FMEC, 2012.

ARAúJO, R. G. Inovação Aberta e o Ecossistema de Fomento. Rumos Economia \& Desenvolvimento, v. 43, p. 303, 2019.

BALESTRIN, A. (2002). Uma análise da contribuição de Herbert Simon para as teorias organizacionais. Disponível em https://www.seer.ufrgs.br/read/article/ view/44111. Acesso em: 05 mai. 2019.

BOGERS, M.; CHESBROUGH, H.; MOEDAS, C. Open Innovation: Research, Practices and Policies. California Management Review, v. 60, n.2, p. 5-16, 2018.

BRETTEL, M.; CHOMIK, C.; FLATTEN, T. C. How organizational culture influences innovativeness, proactiveness, and risk-taking: Fostering entrepreneurial orientation in SMEs. Journal of Small Business Management, v. 53, n. 4, p. 868-885, 2015.

BRUNO-FARIA, M. F.; FONSECA, M. V. A. Cultura de Inovação: Conceitos e Modelos Teóricos, Revista de Administração Contemporânea, v. 18, n. 4, p. 372-396, 2014.

BRUNO-FARIA, M. F.; FONSECA, M. V. A. Medida da Cultura de Inovação: Uma abordagem sistêmica e estratégica com foco na efetividade da inovação. Revista de Administração e Inovação, v. 12, n. 3, p. 56-81, 2015.

ÇAKAR, N. D. ERTÜK, A. Comparing innovation capability on small and medium-sized enterprise: examining the effects of organizational culture and empowerment. Journal of Small Business Management, v. 48, n. 3, p. 353-359, 2010. 
CHESBROUGH, H; BOGERS, M. Explicating Open Innovation: Clarifying an Emerging Paradigm for Understanding Innovation. In: H. CHESBROUGH; W. VANHAVERBEKE; J. WEST (Eds.). New Frontiers in Open Innovation (Chapter 1). Oxford University Press, 2014.

CHRISTENSEN, C. M. O Dilema da Inovação: Quando as Novas Tecnologias Levam Empresas ao Fracasso. São Paulo: M. Books do Brasil Editora Ltda, 2012.

CHRISTENSEN, C. M.; RAYNOR, M.; Mc DONALD, R. (2015). What is Disruptive Innovation? Twenty years after the introduction of the theory, we revisit what it does-and doesn't explain. Harvard Business Review. Disponível em: https://hbr.org /2015/ 12/what-is-disruptiveinnovation. Acesso em: 05 mai. 2019.

COSTA, L. BARBOSA, J. A Cultura Organizacional e Seus Impactos na Formação das Estratégias Empresariais. In: SIMPÓSIO DE EXCELÊNCIA DE GESTÃO E TECNOLOGIA, 7., 2011. https://www.aedb.br/seget/arquivos/artigos11/61514783. pdf. Acesso em: 05 mai. 2019.

DAMANPOUR, F. Organizational innovation: a meta-analysis of effects of determinants and moderators. Academy of Management Journal, v. 34, n. 3, p. 555-590, 1991.

DOBNI, C. B. Measuring innovation culture in organizations: the development of a generalized innovation culture construct using exploratory factor analysis. European Journal of Innovation Management, v. 11, n. 4, p. 534-559, 2008.

DRUCKER, P. F. Innovation and Entrepreneurship: Practice and Principles. New York: Harper Collins Publishers Inc, 1995.

FLEURY, M. T. L.; FLEURY, A. C. C. Aprendizagem e Inovação Organizacional. São Paulo: Atlas, 1996.

GARCIA, R.; CALANTONE, R. A critical look at technological innovation typology and innovativeness terminology: a literature review. Journal of Product Innovation Management, v. 19, n. 2, p. 110-132, 2002.

GREITEMANN, J. et al. Strategic evaluation of technological capabilities, competencies and core-competencies of manufacturing companies. Procedia CIRP, v. 19, p. 57-62, 2014.

GODOY, R. S. P.; PEÇANHA, D. L. N. Cultura organizacional e processos de inovação: um estudo psicossociológico em empresa de base tecnológica. Boletim Academia Paulista de Psicologia, v. 29, n. 1, p. 142-163, 2009.

GUNDLING, E. The 3M way to innovation: balancing people and profit. New York: Vintage Books, 1999.

HOCK, M.; CLAUSS, T.; SCHULZ, E. The Impact of Organizational Culture on a Firm's Capability to Innovate the Business Model. R\&D Management, v. 46, n. 3, p. 433-450, 2016.

HOGAN, S. J.; COOTE, L. V. Organizational culture, innovation, and performance: A test of Schein's model. Journal of Business Research, v. 67, n. 8, p. 1609-1621, 2014. 
HOGAN, S. J.; SOUTAR, G. N.; Mc COLL-KENNEDY, J. R.; SWEENEY, J. C. Reconceptualizing professional service firm innovation capability: Scale development. Industrial Marketing Management, 2011.

JASKYTE, K.; DRESSLER, W. Organizational culture and innovation in nonprofit human service organizations. Administration in social work, v. 29, n. 2, p. 23-41, 2005.

JAMROG, J.; OVERHOLT, M. H. Building a strategic HR function: continuing the evolution. Human resource planning, v. 27, n.1, p. 51-61, 2004.

KAASA, A.; VADI, M. How does culture contribute to innovation? Evidence from European countries. Economics of Innovation and New Technology, v. 19, n. 7, p. 583-604, 2010.

KHAN, Raihan; COX, Pamela. Country culture and national innovation. Archives of Business Research, v. 5, n. 2, 2017.

LACERDA, D. P. Cultura organizacional: sinergias e alergias entre Hofstede e Trompenaars. Revista de Administração Pública, v. 45, n. 5, p. 1285-1301, 2011.

LONGO, F.; NICOLETTI, L.; PADOVANO, A. Smart operators in industry 4.0: A human-centered approach to enhance operators' capabilities and competencies within the new smart factory context. Computers \& industrial engineering, v. 113, p. 144-159, 2017.

MACHADO, D. D. P. N. Inovação e Cultura Organizacional: Um estudo dos elementos culturais que fazem parte de um ambiente inovador. Tese (Doutorado) - Fundação Getúlio Vargas, São Paulo, 2004. Disponível em: https://inovforum.fgv.br/wp-content/uploads/Denise-delPr\%C3\%A1-doutorado.pdf.

MACHADO, D. D. P. N. Organizações Inovadoras: Estudo dos fatores que formam um ambiente inovador. Revista de Administração e Inovação, v. 4, n. 2, p. 05-28, 2007.

MACHADO, D. D. P. N.; VASCONCELLOS, M. A. Organizações Inovadoras: Existe uma cultura específica que faz parte deste ambiente? Revista de Gestão da USP, v. 14, n. 4, p. 15-31, 2007.

MACHADO, D. D. P. N.; CARVALHO, L. C.; HEINZMANN, L. M. Ambiente favorável ao desenvolvimento de inovações e cultura organizacional: integração de duas perspectivas de análise. Revista de Administração, v. 47, n. (4), p. 715-729, 2012.

MACHADO, D. D. P. N.; GOMES, G.; TRENTIN, G. N. S.; SILVA, A. Cultura de Inovação: Elementos da cultura que facilitam a criação de um ambiente inovador. Revista de Administração e Inovação, v. 10, n. 4, p. 164-182, 2013.

MARTINS, E. C.; TERBLANCHE, F. Building organizational culture that stimulates creativity and innovation. European Journal of Innovation Management, v. 6, n. 1, p. 64-74, 2003.

MAVONDO, F.; FARREL, M. Cultural orientation: its relationship with Market orientation, innovation and organizational performance. Management Decision, v. 41, n. 3, p. 241-249, 2003. 
Mc LEAN, L. D. Organizational culture's influence on creativity and innovation: a review of the literature and implications for human resource development. Advances in Development Human Resources, v. 7, n. 2, p. 226-246, 2005.

MENEGHETTI, F. K. Pragmatismo e os pragmáticos nos estudos organizacionais. Cadernos EBAPE, v. 5, n. 1, p. 01-13, 2007.

MENEGHETTI, F. K. O que é um ensaio-teórico?. Revista de Administração Contemporânea, v. 15, n. 2, p. 320-332, 2011.

MINTZBERG, H. Safári da Estratégia: um roteiro pela selva do planejamento estratégico. Porto Alegre: Bookman, 2000.

MORSCHE, E. L.; COSTA, V. L.; REIS, R.; MATOS, E. A. S. A. A Influência da cultura organizacional no processo de inovação: $O$ caso da águia sistemas de armazenagem em Ponta Grossa, Paraná.

RAl - Revista de Administração e Inovação, v. 10, n. 2, p.219-237, 2013.

MORGAN, G. Imagens da Organização. São Paulo: Atlas, 1996.

NAQSHBANDI, M. M.; KAUR, S.; MA, Pin. What organizational culture types enable and retard open innovation? Quality and Quantity, v. 49, n. 5, p. 2123-2144, 2014.

PETTIGREW, A. M. A cultura das organizações é administrável? In: FLEURY, M. T.; FLEURY, A. Aprendizagem e Inovação Organizacional. São Paulo: Atlas, 1996.

PFEFFER, J.; VEIGA, J. Putting people first for organizational success. Academy of Management Executive, 1999.

PISANO, G. P. A Dura Realidade das Organizações Inovadoras. Harvard Business Review Brasil, p. 63-73, 2019.

Organização para a Cooperação e Desenvolvimento Econômico (OCDE). (2005). Manual de Oslo - Diretrizes para coleta e interpretação de dados sobre inovação. Disponível em: https://edisciplinas.usp.br/pluginfile.php/4161223/ mod resource/content/1/ Manual\%20de\%200slo2\%20-\%20FINEP\%20Inovacao.pdf. Acesso em: 20 abr. 2019.

O’REILLY III, C. A.; CHATMAN, J.; CALDWELL, D. F. People and Organizational Culture: a profile comparison approach to assessing person-organization fit. Academy of Management Journal, v. 34, n. 3, p. 487-516, 1991.

REZENDE, J. F. O alinhamento estratégico, o balanced scorecard e o capital intelectual no Brasil: um estudo empírico nas empresas de maior complexidade e repercussão. Tese (Doutorado em Administração) - COPPEAD/UFRJ Rio de Janeiro, 2006.

ROGERS, E. M.; SHOEMAKER, F. F. Communication of innovations. New York: Free Press, 1971.

SCARPIN, M. R. S.; MACHADO, D. D. P. N. O Impacto da Cultura sobre o Ambiente Propício ao Desenvolvimento de Inovações, Revista de Administração e Inovação, v. 12, n. 1, p. 148-173, 2015.

Perspectivas em Gestão \& Conhecimento, João Pessoa, v. 10, n. 1, p. 88-106, jan./abr. 2020. 
SCHEIN, E. H. Coming to a new awareness of organizational culture. Sloan Management Review, v. 25, n. 2, p. 3-16, 1984.

SCHEIN, E. H. How Culture forms, develops, and changes. In: KILMANN, R.; SAXTON, M. J.; SERPA, R. e Associados. Gaining control of the corporate culture (publicado originalmente em 1985). São Francisco: Jossey-Bass Publishers, 1988.

SCHEIN, Edgar H. Organizational Culture and Leadership. São Francisco: Jossey-Bass, 2010.

SCHOENINGER, A.; PACINI, E.; CASAGRANDA, C. (2015, novembro). Influência da cultura organizacional no processo de inovação. Anais do IV SINGEP, São Paulo, SP, Brasil, 1997.

Disponível em: https://singep.org.br/4singep/resultado/466.pdf. Acesso em: 06 mai. 2019.

SCHUMPETER, J. A. Capitalism, Socialism and Democracy (originalmente publicado em 1942). New York: Harper, 1975.

SIMONSEN, J. Herbert A. Simon: Administrative Behavior - How organizations can be understood in terms of decision processes. Computer Science, Roskilde University, 1994.

SOLOMON, G.; WINSLOW, E. K.; TARABISHY, A. The role of climate in fostering innovative behaviour in entrepreneurial SMEs. Business, v. 6, n. 3, p. 24-33, 2002.

SOUSA, M. J.; ROCHA, A. Skills for disruptive digital business. Journal of Business Research, v. 94, p. 257-263, 2019.

STRINGER, R. How to manage radical innovation. California Management Review, v. 2, 1-11, 2000.

TIDD, J.; BESSANT, J. Gestão da Inovação (5a ed.). Porto Alegre: Bookman, 2015.

TROMPENAARS, F. Nas Ondas da Cultura: Como entender a diversidade cultural nos negócios? São Paulo: Educator, 1994.

UNNAMED AUTHORS (?). Organizational Culture. (2017). University of Minnesota Libraries Publishing. Disponível em: https://open.lib.umn.edu/organizationalbehavior/. Acesso em: 20 abr. 2019.

VAN DE VEN, A. H.; ANGLE, H. L.; POOLE, M. S. Research on the management of innovation: the Minnesota studies. New York: Oxford University, 2000.

VAN MAANEN, J. Processando as pessoas: estratégias de socialização organizacional. In: FLEURY, M. T.; FLEURY, A. Aprendizagem e Inovação Organizacional. São Paulo: Atlas, 1996.

WORLD ECONOMIC FORUM (WEF). (2018). The Readiness for the Future of Production Report. Disponível em: http://www3.weforum.org/docs/FOP Readiness Report 2018.pdf. Acesso em: 20 abr. 2019.

WINTER, S. G. Understanding dynamic capabilities. Strategic Management Journal, v. 24, n. 10, p. 991-995, 2003.

Perspectivas em Gestão \& Conhecimento, João Pessoa, v. 10, n. 1, p. 88-106, jan./abr. 2020. 
YOGGI, R. Framework de Inovação, Modelo Aberto, para Gestão da Inovação nas Organizações Modernas. Creative Commons. Disponível em: https://pt.sli deshare.net/RicYog/paper-modelo-ryo-pgi-plano-de-gesto-da-inovao-2015-r04. Acesso em: 20 abr. 2019.

YOGGI, R. Framework de Inovação para Organizações Modernas. Project Design Management, v. 15, n. 75, p. $68-73,2017$.

ZALTMAN, G.; DUNCAN, R.; HOLBEK, J. Innovations and organizations. New York: Wiley, 1973. 